\title{
Torres de vigilancia en la costa del antiguo reino de Granada (S XV-XVIII)
}

\section{Whatchtowers on the old Granada kingdom coast (XV-XVIII centuries)}

\author{
M. Fernández Cánovas ${ }^{(*)}$
}

\section{RESUMEN}

A lo largo de nuestras costas mediterráneas nos encontramos con una serie continua de torres de diferentes formas situadas en altozanos que dominan el mar, separadas, unas de otras, a la distancia suficiente para que puedan verse y comunicarse entre sí con facilidad. Son torres de vigilancia o torres almenaras, que detectan la aproximación de embarcaciones intrusas que llegan del norte de África con intenciones poco pacíficas. A estas torres - patrimonio histórico, cultural y turístico- que se construyeron entre los siglos XV y XVIII, se refiere este artículo en el que de forma somera se describe su importancia defensiva a lo largo del tiempo, su organización, su tipología, materiales empleados en su construcción y su conservación.

Palabras clave: Torres vigías; torres almenaras; defensa costera; Reino de Granada.

\section{ABSTRACT}

Throughout our Mediterranean coasts, there is a continuing series of towers of different shapes located in small hills above the sea, separated from each other far enough to be seen and able to communicate with each other. They are watchtowers that detect the proximity of intrusive boats that arrive from Northern Africa with no pacific intentions. It is to these towers - historical, cultural and touristic heritage - that were built between the XV and XVIII centuries, that we dedicate this article in which, in a brief manner, their important defensive mission through time and also their organization, typology, the materials used for their construction and their maintenance are described.

Keywords: Watchtowers; beacon towers; coast defense; Granada Kingdom.

(*) Dr. Ing. Construcción. Prof. Emérito Universidad Politécnica de Madrid (España). Persona de contacto/Corresponding author: mfcanovas2@telefonica.net (M. Fernández). ORCID: https://orcid.org/oooo-0001-6575-3802 (M. Fernández).

Cómo citar este artículo/Citation: Fernández Cánovas, M. (2019). Torres de vigilancia en la costa del antiguo reino de Granada. (S XV-XVIII). Informes de la Construcción, 71(553): e276. https://doi.org/10.3989/ic.67478

Copyright: (C) 2019 CSIC. Este es un artículo de acceso abierto distribuido bajo los términos de la licencia de uso y distribución Creative Commons Reconocimiento 4.o Internacional (CC BY 4.0). 


\section{INTRODUCCIÓN}

El sistema de alerta y comunicación proporcionado por las torres vigías no es nuevo. La Biblia nos habla en alguno de sus pasajes de esta forma de transmitir los peligros mediante señales de humo o por medio de fogatas.

En tiempos de los fenicios y cartagineses estas torres tenían mucha importancia. El mismo Tito Livio, que vivió entre los años 59 y 19 A.C., al describir una de las batallas de la segunda Guerra Púnica, dice: "Los de Ceo Scipion no pudieron atacar por sorpresa a las fuerzas de Asdrubal, acampadas en la desembocadura del río Ebro, por el oportuno aviso de una de estas vigilancias". Tito Livio indicó también: "España tiene en lugares altos emplazadas muchas torres usadas como atalayas y defensa contra ladrones".

La inseguridad en la costa mediterránea siempre ha existido y ésta ha sido mucho más intensa en la costa andaluza por la proximidad a África y la facilidad de pasar el Estrecho en embarcaciones de vela. Los secuestros, saqueos, incendios, matanzas, etc., que producían los piratas berberiscos, corsarios o, simplemente, ladrones eran muy frecuentes.

En época romana el peligro en las costas fue grande hasta que Pompeyo decidió reprimir las incursiones griegas y fenicias. Con la caída del Imperio Romano, en el siglo III, vuelven en España a iniciarse las incursiones que fueron fuertes en la época visigoda, hasta que con el califato de Córdoba se organiza una defensa muy eficaz que decae en las postrimerías del reino de Granada. Es curioso en hecho de relata J.A. Cebrian (1), en "La aventura de la Reconquista", en el que indica que: "En el año 844 la Península Ibérica recibe la visita de las terribles hordas vikingas que arrasaron La Coruña, luego Lisboa y posteriormente, subiendo por el Guadalquivir, la ciudad de Sevilla. Abderramán II les presentó batalla y las derrotó en Tablada y en previsión de futuros ataques orde- nó la construcción de atalayas defensivas por toda la costa mediterránea”.

La franja litoral que comprende las actuales provincias de Málaga, Granada y Almería constitutivas del antiguo reino de Granada, con una extensión aproximada de unos 277 kilómetros y que se extendía desde la desembocadura del río Guadiaro hasta la del río Almanzora (Fig. 1), llegó a tener un gran protagonismo y fue motivo de fuertes preocupaciones para los monarcas cristianos al finalizar la Reconquista. Los primeros afectados fueron los Reyes Católicos que conscientes del peligro que presentaban para la paz la llegada de naves turcas y bereberes, especialmente a la costa del reino de Granada, mandaron en el 1497, reparar las torres existentes, de origen nazarí, que tanto habían dificultado con anterioridad los ataques a esas tierras en poder morisco de las flotas castellano-aragoneses, y demoler las que no fuesen útiles, construyendo nuevas torres de acuerdo con el plan defensivo que los reyes tenían proyectado. A su vez ordenaron y libraron los recursos económicos para que las flotas al mando de don García López de Arriaran y de don Juan de Lazcano, recorrieran y vigilasen en sentido opuesto la costa (2).

Para evitar acciones de espionaje y de posible ayuda a los piratas bereberes se ordena ejercer un control sobre los moros y conversos que viven a la costa otorgándoseles una cédula de identificación y limitando sus desplazamientos cuando salen a pescar. La vigilancia se intensifica con la llegada de corsarios turcos y las incursiones de Solimar, Barbarroja y "Cachidemonio" entre los años 1502 y 1591 (3).

El S. XVII fue muy preocupante para la corona al ocurrir el saqueo de Adra y por el temor a una toma inminente de Málaga, lo que dio lugar a disponer, por parte de Felipe II, medidas muy especiales para la defensa de esta ciudad. La mejora de la seguridad costera continuó después con Felipe V, Fernando VI y Carlos III, quien, en 1764, establece un plan

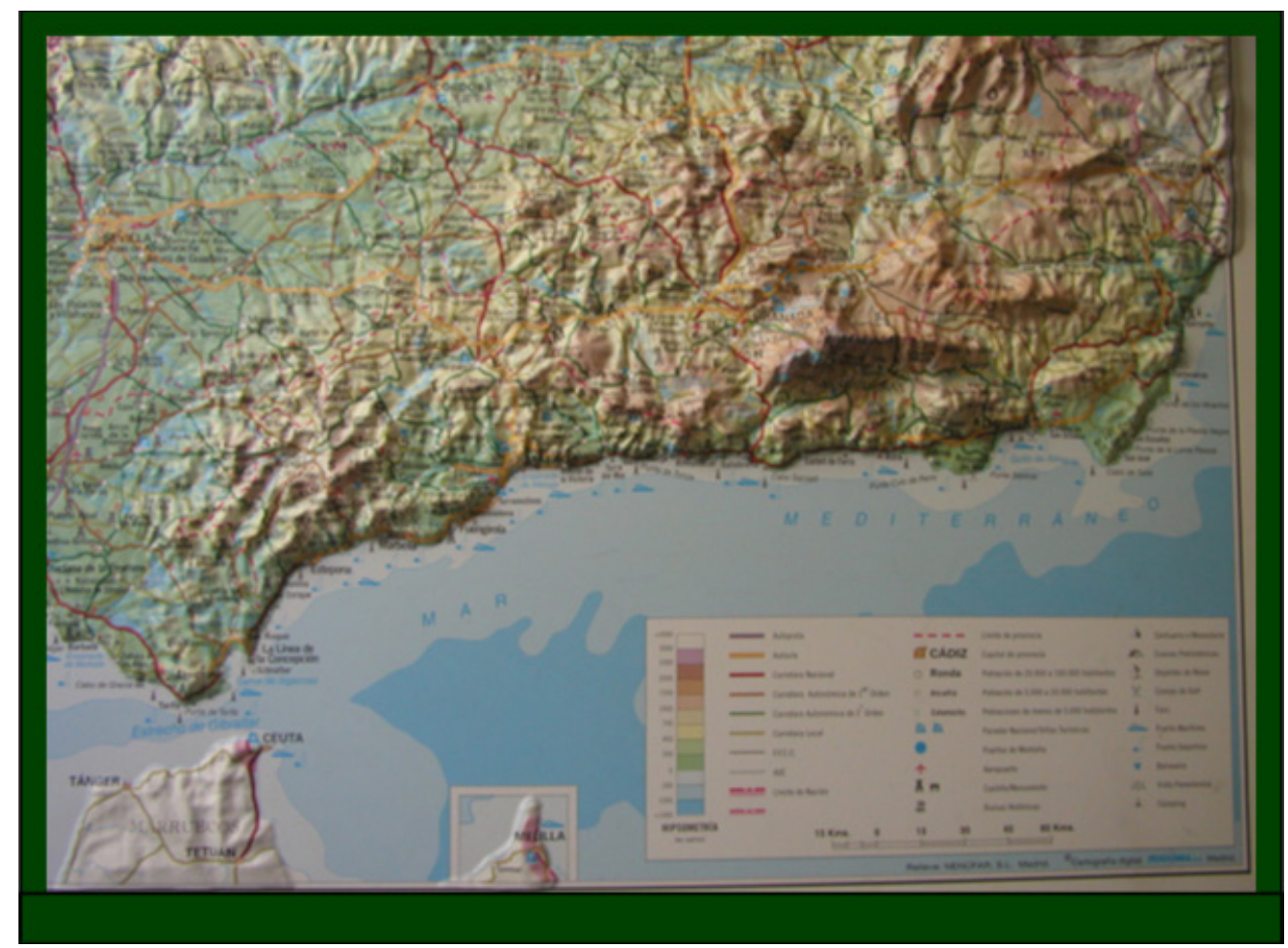

Figura 1. Trozo de la costa que correspondía al reino de Granada. 
defensivo que mediante la coordinación de las fortificaciones útiles existentes, baterías artilleras de diferentes calibres, casas fuertes abaluartadas y torres vigías, permite crear una barrera defensiva a lo largo de la costa del reino de Granada que impida que cualquier navío considerado como enemigo, pueda acercarse a un embarcadero del litoral. Se puede decir que fue en el S XVIII cuando se alcanzaron niveles de gran eficacia, pues con Fernando VI solo se habían realizado labores de mantenimiento de las defensas existentes.

Al finalizar la guerra de la Independencia y la retirada de Napoleón, las tropas francesas desmantelaron las defensas costeras lo que causó gran satisfacción a los ingleses, dado que la costa mediterránea era una presa fácil para los ingleses desde su base en el peñón de Gibraltar ocupado en 1704. Esta barrera frenaba las acciones de corso de su flota en nuestras costas que obedecía fielmente las normas de: “Es más fácil apresar un navío que construirlo y armarlo en un astillero, es más fácil robar mercancías que adquirirlas en el mercado, es más fácil secuestrar a un esclavo que pagar a un jornalero, etc.”. Fernando VII trató de restaurar algunas torres destruidas por los franceses con los pocos recursos que disponía, como se deduce de los informes que encargó el monarca a Miguel de Santillana en los que se considera a las torres como un valioso dispositivo para las comunicaciones militares. Aunque realmente el sistema ya había quedado obsoleto ante los avances de la artillería naval y de los sistemas de desembarco, las torres seguían ejerciendo un papel de vigilancia. Estas estaban a cargo del cuerpo de ingenieros militares dependiente, en el caso que nos ocupa, del Capitán General de Granada, hasta que por orden del Ministerio de la Guerra, en 1850, pasan a depender del cuerpo de Carabineros y posteriormente, en 1941, de la Guardia Civil, ahora con un carácter más bien policial y de vigilancia.

Ante el deterioro, muchas veces provocado, que sufren las torres y fortalezas costeras, por Real Decreto de 15/11/1889 queda prohibida la demolición de cualquier obra de defensa, por insignificante que pueda ser considerada. Este RD se actualiza con el Decreto de 22/4/1949 que crea un marco legal que protege, teóricamente, a las torres, dado que en su artículo $1^{\circ}$ se indica que: "Todos los castillos de España, cualquiera que sea su estado de ruina, quedan bajo la protección del estado que impedirá toda intervención que altere su carácter o pueda provocar su derrumbamiento."

\section{ORGANIZACIÓN}

Las torres vigías de los siglos XV al S. XVIII estaban emplazadas y algunas siguen estándolo, en promontorios de la costa de tal forma que desde ellas se pueden ver a sus inmediatas laterales situadas entre 2 y $4 \mathrm{~km}$ de distancia, dando lugar a la formación de una cadena continua defensiva. Muchas de ellas están situadas junto a riachuelos de los que se abastecen de agua. Los avisos entre ellas, con humo de día y fogatas, o hachos de noche, eran suficientes para que muchos barcos enemigos huyesen. Cuando esto no ocurría, desde el segundo escalón de la cadena situado más a retaguardia, formado por fortines y castillos, se enviaban rápidamente tropas de caballería que hundían a las embarcaciones y detenían a los asaltantes en caso de su desembarco.

En cada torre vigía solía haber tres torreros, uno, el "escucha" de vigilancia permanente, que se relevaba por turnos, y los otros dos, que además de la de vigilancia tenían la misión de ir cada día a la torre contigua para tomar contacto con la guarnición de la misma (Fig. 2). El conjunto de las torres de una zona era inspeccionada por un "atajador" y a los atajadores y torreros de una zona los supervisaba un "requeridor". Los requeridores, así como los "visitadores" o "veedores", que era el mayor cargo y responsabilidad que se podía alcanzar, dependían del obispado correspondiente, en el caso de la costa malagueña del Obispo de Málaga. Cada dos meses los veedores tenían que redactar con el Escribano Mayor de la Corte un informe o memoria sobre el estado en que se encontraba el sistema defensivo, así como de las incidencias habidas y los gastos originados (4).

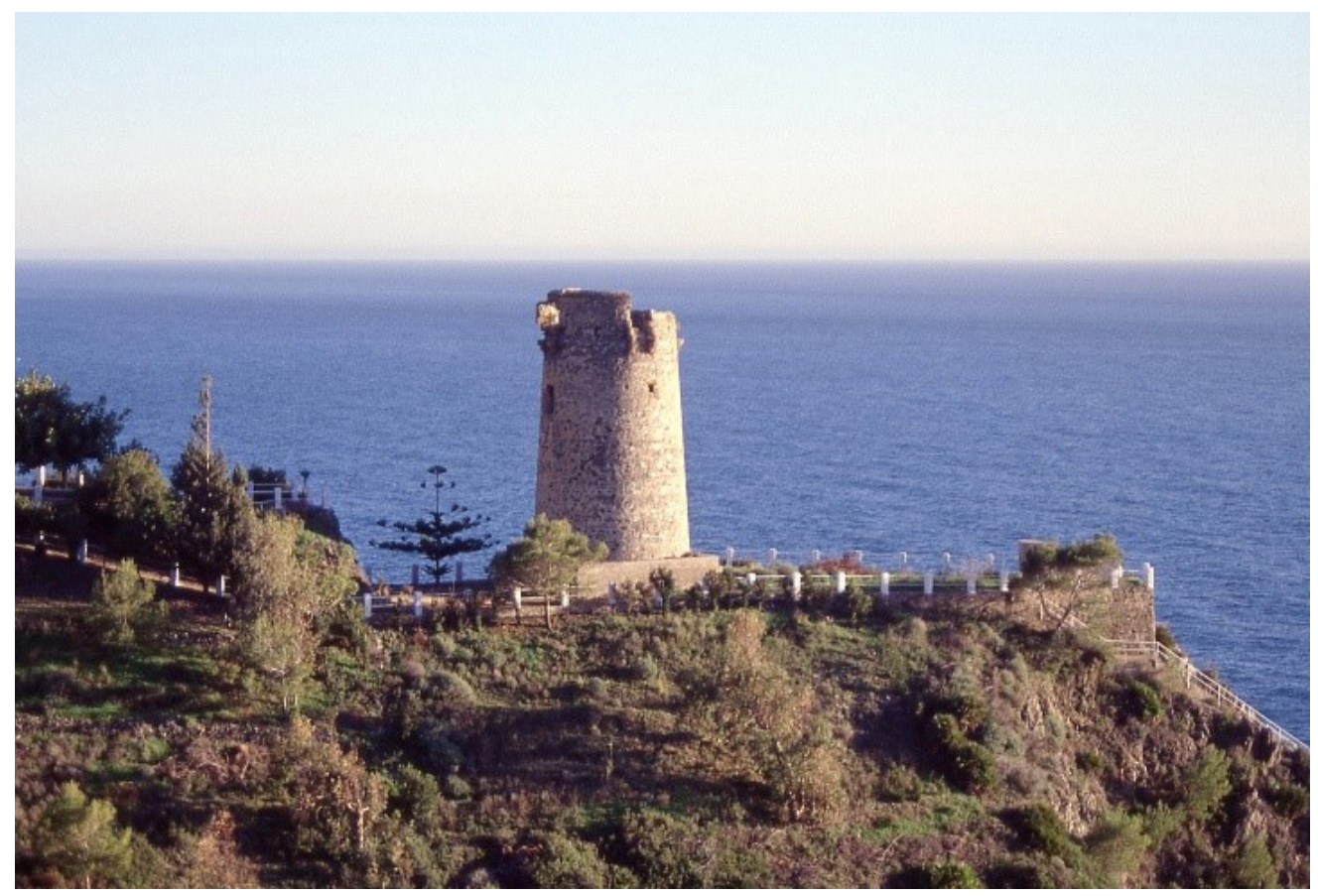

Figura 2. Torre del Pino (Torrox). 
El modus operandi de la defensa, en los primeros tiempos, consistía en lo siguiente: cuando era avistaba una nave sospechosa por el sector correspondiente a una torre, ésta encendía paja húmeda si era de día, o bien con fuego si era noche, y hacía señales a las dos torres situadas a sus costados, las que a su vez las emitían a las siguientes. La señal era diferente según la magnitud del peligro. Si era pequeña, los torreros con ayuda de los vecinos de las estancias próximas, podían repeler a los enemigos. Si la señal indicaba que el peligro era grave, al llegar ésta a una Casa fuerte, situada en el segundo escalón defensivo, se desplazaban tropas de caballería para repeler al enemigo. Si el peligro era aún mayor por el número de naves y personas implicadas en él, al llegar la señal de arrebato a los castillos emplazados en el tercer escalón defensivo se producía un desplazamiento importante de tropas de caballería y de infantería hacia el lugar en peligro. Los castillos estaban situados en poblaciones importantes como Estepona, Marbella y Sohail en Fuengirola, San Miguel en Almuñécar, Cuevas de Almanzora en Almería, etc.

La actividad de las torres fue intensa en 1502, inmediatamente después de la Reconquista, por el ataque de armadas mahometanas; en 1511 por galeras y fustas turcas; en 1520 por corsarios turcos y bereberes y posteriormente, entre 1540 y 1545 , como se ha indicado anteriormente, por piratas de la categoría de Solimar y Barbarroja.

Las primeras medidas oficiales de organización de la vigilancia costera datan de 1491, si bien la Ordenanza que las regula, firmada por los Reyes Católicos, entra en vigor en 1492. Es precisamente en los últimos años del siglo XV cuando se organiza seriamente la defensa, cuando se crean nuevas estancias en lugares estratégicos y cuando se contratan peones para el servicio de las torres, estableciéndose, además, un tributo o impuesto para el mantenimiento de estas defensas que debían cobrar los "cogedores", o recaudadores de impuestos, que solían ser mudéjares dado que se entendían bien con los moros reacios a pagar dichos tributos.

El 1 de agosto de 1501 se promulga en Granada la "Instrucción para las guardas de la costa de la mar" en la que se recogía una normativa muy completa en cuanto a la organización de la defensa que llevó consigo un avance muy importante en la misma. En la Instrucción se recogía el perfil de los "escuchas" o vigilantes de las torres, de los que se decía que habian de ser; "onbres del campo o mancebos resueltos e sanos que tengan conocimientos de las cosas de la mar y de la tierra". Como es lógico la organización fue cambiando con los tiempos y haciéndose cada vez más eficaz dado que las amenazas, procedencia y motivos fueron cambiantes, como lo demuestra el hecho que después de la Guerra de Sucesión el peligro pasó a ser el corso de las naves inglesas que tenían sus bases en Menorca y Gibraltar.

\section{TIPOS DE TORRES DE VIGILANCIA Y DEFENSA}

En el siglo XV la costa mediterránea que comprendía el antiguo reino de Granada, estaba vigilada por simples torres almenaras y algunos castillos situados en núcleos poblacionales importantes. Con el paso del tiempo el peligro de incursiones enemigas se intensificó, no sólo por el número de los atacantes que tomaban parte en ellas sino también por capacidad destructiva de las armas que utilizaban y por la procedencia de sus bases. Esto dio lugar a que se produjese una evolución en la defensa y consecuentemente en su organización acorde con las nuevas amenazas. Así, las defensas del siglo XVIII, sin dejar de lado a las torres vigías eran fuertes adecuadamente artillados y muy bien guarnecidos.

Fundamentalmente, en el tramo de costa que consideramos hay que distinguir, tres tipos de torres vigías que según la forma de su planta pueden ser: cuadradas, circulares (generalmente, ambas de origen árabe) que datan del siglo XV y las más modernas llamadas de "pezuña", por su planta en forma de herradura, que se implantaron en el siglo XVIII. El tipo de torre predominante en la costa que correspondía al reino de Granada, es la troncocónica de planta circular - aunque alguna vez se encuentre alguna cilíndrica - ; las de planta cuadrada son escasas al igual que lo son las de pezuña.

Los "fuertes artillados" o "fuertes-baterías" como se suelen denominar, son propios del siglo XVIII y construidos por Carlos III con misión de impedir, fundamentalmente, el ataque corsario inglés. Estos fuertes-batería son muy completos desde el punto de vista defensivo y están situados muy próximos a las playas disponiendo de una guarnición de soldados de infantería, artillería y caballería. Obedecen a un tipo de fortificación que en un único reciento dispone de una plataforma con una batería de cañones, y un fuerte donde se alojan la tropa y los caballos.

Dentro de este grupo y por ser del mismo siglo XVIII podemos considerar el Fuerte de Bezmiliana, próximo al Rincón de la Victoria de Málaga, destinado fundamentalmente a albergar un destacamento de infantería y de caballería. Solo existe uno en la costa malagueña y otro en la almeriense en el Playazo de Rodalquilar de propiedad privada.

\subsection{Torres cuadradas}

Las torres de planta cuadrada suelen ser de origen nazarí y por tanto anterior a los Reyes Católicos. Tienen como misión principal la vigilancia, siendo por tanto altas y delgadas y con paredes verticales. A muchas de ellas ha habido que hacerles posteriormente un recrecido en su base para amortiguar la oscilación del viento. Suelen estar construidas con mampostería de piedra y verdugadas de ladrillo, siendo también de este material las esquinas. No son tan frecuentes como las torres de planta circular y sus dimensiones varían de unas a otras de forma sustancial. En el trozo de costa de litoral que nos ocupa podemos encontrarnos con: La torre de la Sal, o Salto de la Mora (Fig. 3), torre de Guadalmansa, torre del Duque (en pleno centro de Marbella), torre de Ladrones, torre de los Molinos (en pleno centro de Torremolinos), torre del Jaral y torre del Tesorillo. Nos hemos detenido en dos de ellas: la "Torre del Salto de la Mora" y la "Torre de los Ladrones" por su singularidad.

La torre del Salto de la Mora conocida también por la Torre de la Sal, por haber servido en el siglo XVIII como almacén para un industria de salazones próxima a ella. Esta torre, de la que hace una magnifica descripción Juan Tembpory en su libro "Torres almenaras" (5), está situada a $91 \mathrm{~km}$ de la ciudad de Málaga en el término municipal de Estepona y próxima al límite con la provincia de Cádiz. Al parecer, servía de acuartelamiento de una pequeña guarnición y a la vez de torre vigía.

La torre posee planta cuadrada de 9,20 m de lado y de 10,60 $\mathrm{m}$ de altura, teniendo la entrada por una puerta situada a $5,40 \mathrm{~m}$ en la fachada norte opuesta al mar. Los muros son de 


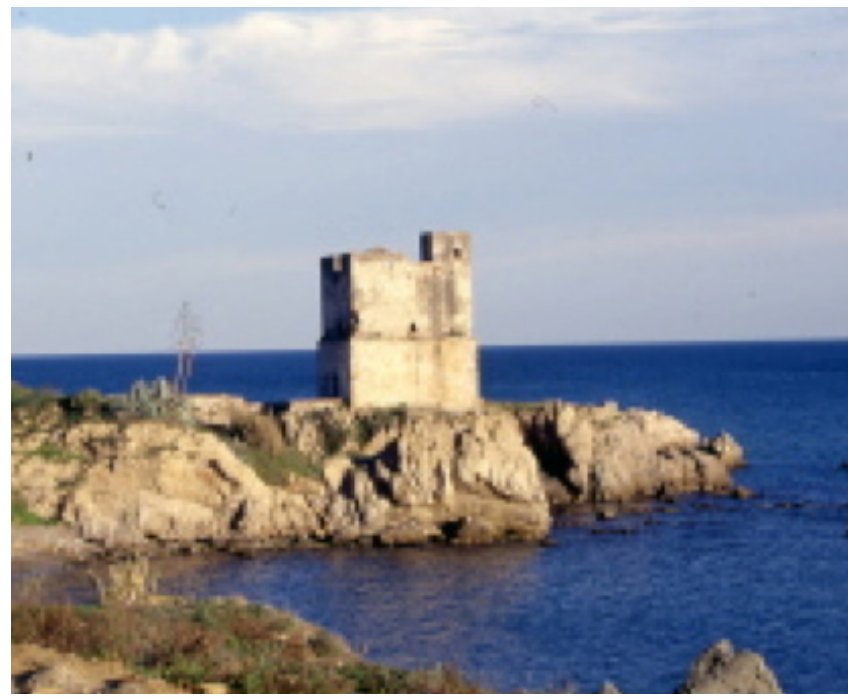

Figura 3. Torre de la Sal o del salto de la Mora.
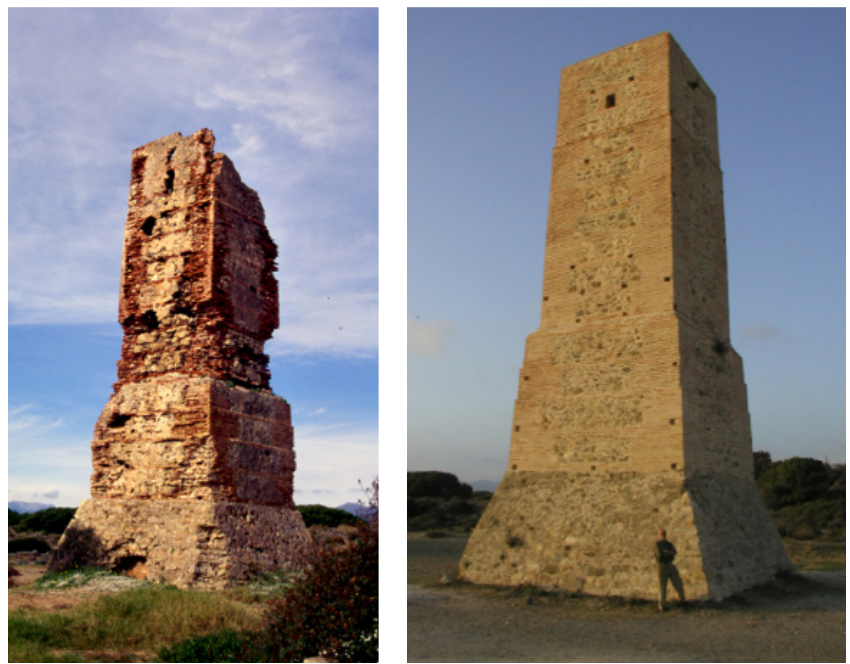

Figura 4. Torre Ladrones antes y después de su restauración por el Arq. Cesar Olano.
1,35 m de espesor. La parte interior de la torre está formada por dos cámaras de 6,50 m de lado cubiertas con bóvedas octogonales vaídas, preciosas, construidas con ladrillo con dos roscas. Posee dos tramos de escaleras empinadas dando acceso la última a un terrado cuadrado de $8,0 \mathrm{~m}$ de lado protegido a su alrededor por un pretil aspillado de 1,10 $\mathrm{m}$ de alto y 0,62 $\mathrm{m}$ de espesor. Existen unas ménsulas que indican que en su día la torre tuvo matacanes.

La sala principal, en primera planta, posee huecos de medio punto en los muros norte y sur para vigilancia y en ella se conserva la chimenea para producir el humo de alarma que es conducido hasta el terrado saliendo por un hueco del mismo. En el terrado existe una garita cuadrada de 1,80 m de lado cubierta con bóveda esférica de ladrillo.

La torre del Salto de la Mora, conserva muy bien sus bóvedas octogonales vaídas propias de la arquitectura árabe.

Otras torres de planta cuadrada de la costa son la "Torre de los Molinos" que dio nombre al pueblo de Torremolinos y que se conserva en buen estado y la "Torre Ladrones" en el término municipal de Marbella. Esta última, también nazarí, construida con ladrillo tosco de gran calidad y próxima a la playa, tiene una gran esbeltez lo que hizo que las condiciones ambientales, especialmente el viento con salitre, destruyesen su parte superior. Hace unos años fue restaurada, con gran mimo, por el arquitecto malagueño y amigo, Cesar Olano, gran especialista en este tema que hasta llegó a montar un tejar para fabricar artesanalmente los ladrillos para la torre, al igual que se hacían en el siglo XV (Fig. 4).

Cesar Olano decía: "En una restauración de una torre hay que hacer un inventario detallado de la misma y de su estado, un estudio profundo, así como una ortopedia previa donde fuere necesario para luego acometer la restauración definitiva. Las torres son, en sí mismas, como un documento en el que los arqueólogos y los historiadores pueden leer; por ello, el arquitecto con su trabajo, debe evitar en todo momento borrar datos que puedan ser de utilidad para la investigación".

Siete es el número de torres de planta cuadrada existentes en el tramo de costa que consideramos.

\subsection{Torres circulares}

Las torres de planta circular son típicas de la primera fase de fortificación que tiene lugar después de la Reconquista. Al tener muchas de ellas misión de vigilancia y defensa se construían con mampostería. El muro circular de su contorno es generalmente inclinado, dando lugar a que la torre sea troncocónica, al objeto de que el impacto de los proyectiles enemigos hiciese menos mella sobre el mismo. Por este mismo motivo, el espesor del muro es muy superior al de las torres de planta cuadrada. Generalmente disponen de una ventana de vigilancia orientada al mar a los dos tercios de su altura. La puerta de acceso se sitúa a la misma altura por la parte opuesta haciéndose el acceso a la torre por medio de una escala de cuerda que se retira al interior una vez usada. Tanto las ventanas como la puerta de acceso suelen estar protegidas por matacanes.

La gran mayoría de las torres que hemos catalogado en el tramo de costa que comprende la de Málaga, Granada y parte de Almería, pertenecen a este tipo constructivo. Según nuestros datos son 56 el número de torres de este tipo en nuestro trozo de costa.

A título de ejemplo describimos la "Torre de Calaburras" situada en el termino municipal de Mijas y a unos $32 \mathrm{~km}$ de la ciudad de Málaga. Esta torre se encuentra enclavada en un promontorio que entra en el mar, junto al faro de Calaburras, dominando un amplio sector comprendido entre la "Torre Nueva" de La Cala de Mijas y las torres de Benalmádena. Pertenece a un grupo de torres de características similares construidas en el año 1515 (Fig. 5).

La torre está construida con mampostería de piedra caliza oscura tomada con cal (cal y canto) y conserva restos de enfoscado de su revestimiento primitivo. Su altura es de 13,40 $\mathrm{m}$, con diámetros inferior y superior de 7.90 y $5,75 \mathrm{~m}$, respetivamente. La entrada a la torre se hacía por una ventana situada a 8,50 m de altura. La parte inferior de la misma hasta la mitad de su altura es maciza y en la parte superior disponía de una sola estancia en la que estaba situado un hogar para producir el humo que salía por una chimenea en el terrado, y por supuesto una escalera para acceder al mismo donde se hacían las labores de vigilancia y las fogatas por la noche en caso de alarma. 


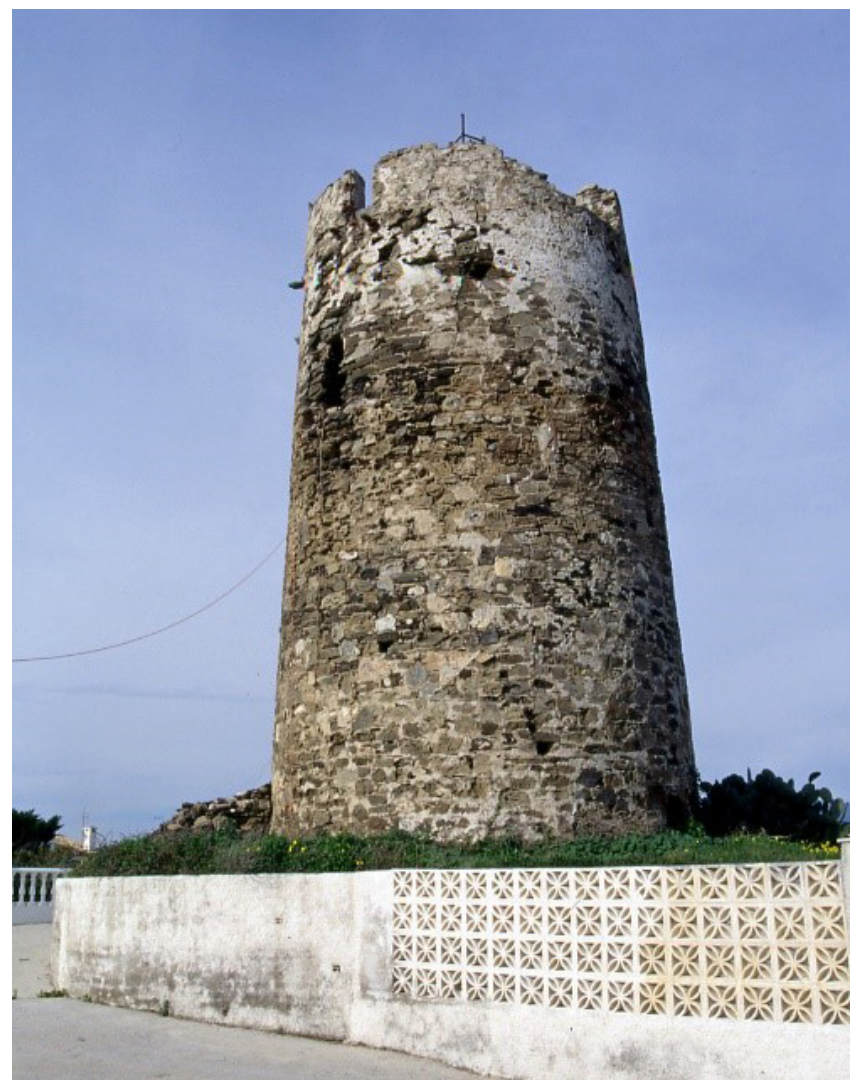

Figura 5. Torre de Calaburras (Mijas).

La guarnición era la típica de estas torres, un cabo y dos torreros. Para compensar su escaso sueldo se les permitía que tuviesen un trozo de tierra de labor próxima a la torre. Esta permisión fue muy criticada y controvertida pues se decía que la huerta les distraía y les restaba tiempo que debían dedicar a la vela.

Para darnos una idea de la densidad de torres a lo largo de los 150 kilómetros de la costa dependiente de Obispado de Málaga, diremos que en el año de 1511 había 44 torres.

\subsection{Torres de pezuña}

Antes de que los turcos fuesen vencidos en la Batalla de Lepanto en 1571, sus incursiones piratas en la costa mediterránea y especialmente en la del sur, eran muy frecuentes y en ellas empleaban navíos de gran porte y bien artillados. Para hacer frente a esta amenaza se construyen las torres de "pezuña" con un gran terrado para emplazar en él piezas de artillería. Los paramentos de las torres eran inclinados para favorecer el rebote de los proyectiles enemigos, siendo las torres suficientemente bajas para que el tiro rasante de los cañones propios pudiese impactar en primera trayectoria sobre los barcos.

Parece ser que estas torres tuvieron su origen en Italia donde existían algunas parecidas en Córcega y Cerdeña, lo que no descarta la posibilidad de que fuesen diseñadas por un maestro fortificador italiano. En cualquier caso, se trata de torres muy sólidas y verdaderas fortalezas que, aparte de su misión de vigilancia y transmisión de señales tenían la de defensa, ya que a diferencia de las circulares y cuadradas éstas estaban artilladas con dos cañones de 16 libras, disponiendo de una guarnición de 10 artilleros y 16 infantes (Fig. 6).

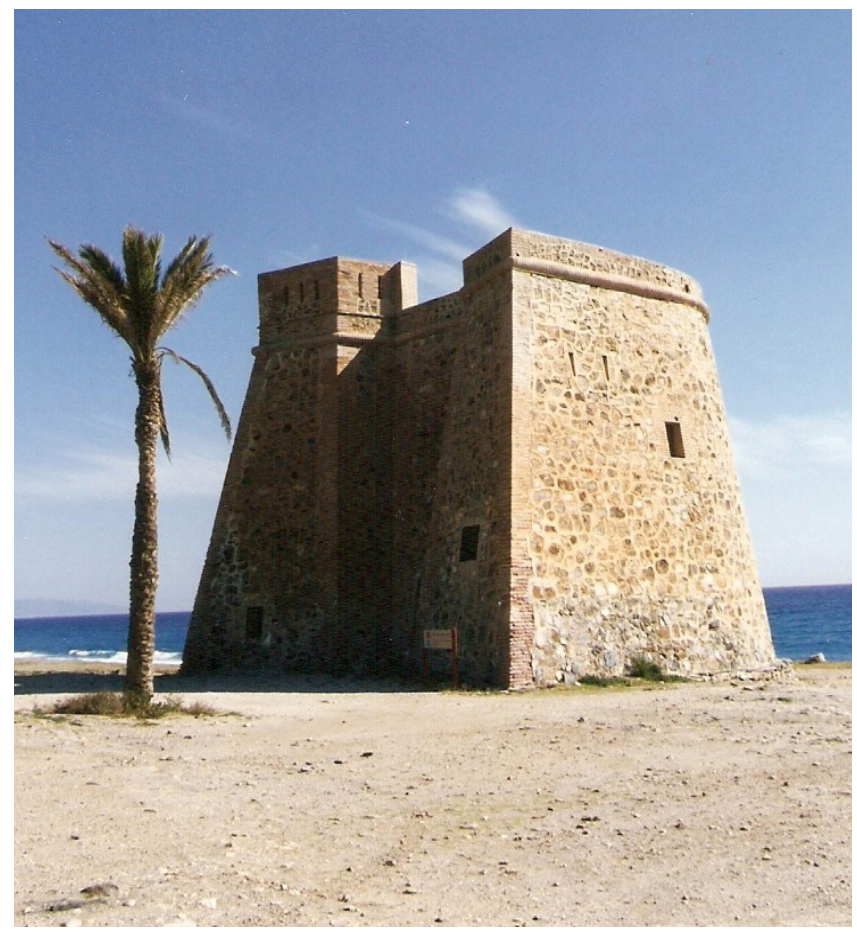

Figura 6. Torre de la Peña (Mojácar).

Actualmente hay ocho torres de este tipo en la zona de costa que estamos considerando, tres de ellas en la malagueña: Torre del Lance de las Cañas, Torre de La Cala de Mijas y Torre de Moya; dos en granadina: Torre de Punta Galera o del Tesorillo y Torre de Baños (en la Marmola), y tres en la almeriense: Torre de Mesa Roldán, Torre de Mecenas y Torre de Cristal o Villaricos, junto al río Almanzora.

A título de ejemplo vamos a describir, siguiendo a Juan Temboury, la Torre de la Cala situada en el término municipal de Mijas Costa, a $36 \mathrm{~km}$ de la ciudad de Málaga (Fig. 7). Esta torre se encuentra perfectamente conservada y ha sido restaurada con gran acierto y dedicada a sala de exposiciones y oficina de turismo. La torre está construida con mampostería de cal y canto y las esquinas de los espolones, dinteles y jambas están formadas por aparejo de ladrillos muy bien cocidos de 31x15x4 cm con llagas de $3 \mathrm{~cm}$ de espesor. Su forma es de semicírculo prolongado y cerrado por dos hornabeques. El radio de la base es de 7,30 $\mathrm{m}$ y la altura de $10,85 \mathrm{~m}$, siendo el desplome de los muros de $85 \mathrm{~cm}$ lo que dificulta se escalada. La entrada a la estancia principal que tiene unas dimensiones de 8,38 x 5,23 m., se hacía por un hueco situado a $6,0 \mathrm{~m}$ de altura en el lado oriental del espolón derecho, estando protegida por saeteras laterales. De esta estancia se bajaba por una escalera a una sala inferior o baja de 6,85 x 5,10 m y por la misma escalera se subía al terrado de 10,20 x 6,35 m. Las dos estancias están cubiertas por bóveda de ladrillo. La principal posee dos ventanas de iluminación y vigilancia que dominan la costa. En esta sala se encuentra una gran chimenea para hacer humo de señales y en el centro del suelo un hueco circular que ilumina la planta baja y sirve para elevar municiones desde la santabárbara situada en el sótano.

El terrado está situado a 10,85 m del suelo y rodeado de un pretil de $0,70 \mathrm{~m}$ de alto y $1,10 \mathrm{~m}$ de espesor, teniendo una salida de humos de señales procedentes de la chimenea y una mesa para hacer fogatas. En la parte circular del torrado se 
encuentran los emplazamientos para los cañones y coincidiendo con los dos espolones hay dos torretas cuadradas, con aspilleras en sus costados, de protección de los vigilantes, que probablemente se adicionaron en el siglo XVIII.

\subsection{Fuertes-batería}

Los Fuertes-batería están formados por una plataforma semicircular elevada orientada hacia el mar, construida con muros inclinados de piedra y coronada por un pretil, donde se emplaza una batería de artillería (Fig. 8).

La plataforma se une por la gola a un fuerte de planta cuadrada situado a un nivel más bajo y al que se accede por una escalera. El fuerte de planta cuadrangular de unos $36 \mathrm{~m}$ de lado, dispone de un patio central a cuyos lados se levantan dos naves que sirven para alojamiento de la tropa, de cuadras para los caballos, cocinas, aseos, almacenes, polvorín y una pequeña capilla. Los muros exteriores son de piedra de gran espesor y las naves están cubiertas por bóvedas de ladrillo de dos roscas.

El recinto tiene gran y sólido portón de entrada en la parte opuesta al mar y está protegido por un foso y puente levadizo. En esquinas opuestas dispone de dos garitas de vigilancia con aspilleras que dominan todo el contorno del reciento. La guarnición solía estar formada por 10 soldados de infantería, 5 artilleros y 13 soldados de caballería que se ocupaban estos últimos de los 8 caballos disponibles.

La torre-batería que hemos descrito se corresponde con la de "San José de La Garrucha”, y forma parte de un grupo de torres iguales, mandadas construir en la costa por Carlos III, dentro del tramo de litoral que nos ocupa. Las torres que actualmente existen se conocen con los nombres de: Castillo de la Duquesa, Fuerte-batería de la Herradura, Castillo de Guardias Viejas, Fuerte-batería de San Ramón, Fuerte-batería de Jesús Nazareno y Fuerte-batería de San José.

\subsection{Casas fuertes}

Son fortificaciones abaluartadas de las misma época de los fuertes-baterías, es decir del siglo XVIII. En la costa malagueña solamente existe la casa fuerte de Bezmiliana situada en el Rincón de la Victoria de Málaga. Esta formada por un recinto cuadrangular de 27,8 x 25,6 m cerrado por muros gruesos de mampostería pétrea que en dos de sus ángulos opuestos dispone de torreones. o garitones, circulares de defensa. Dispone en su interior de una nave de dos plantas cubiertas por bóvedas de medio cañón de ladrillo. Su misión

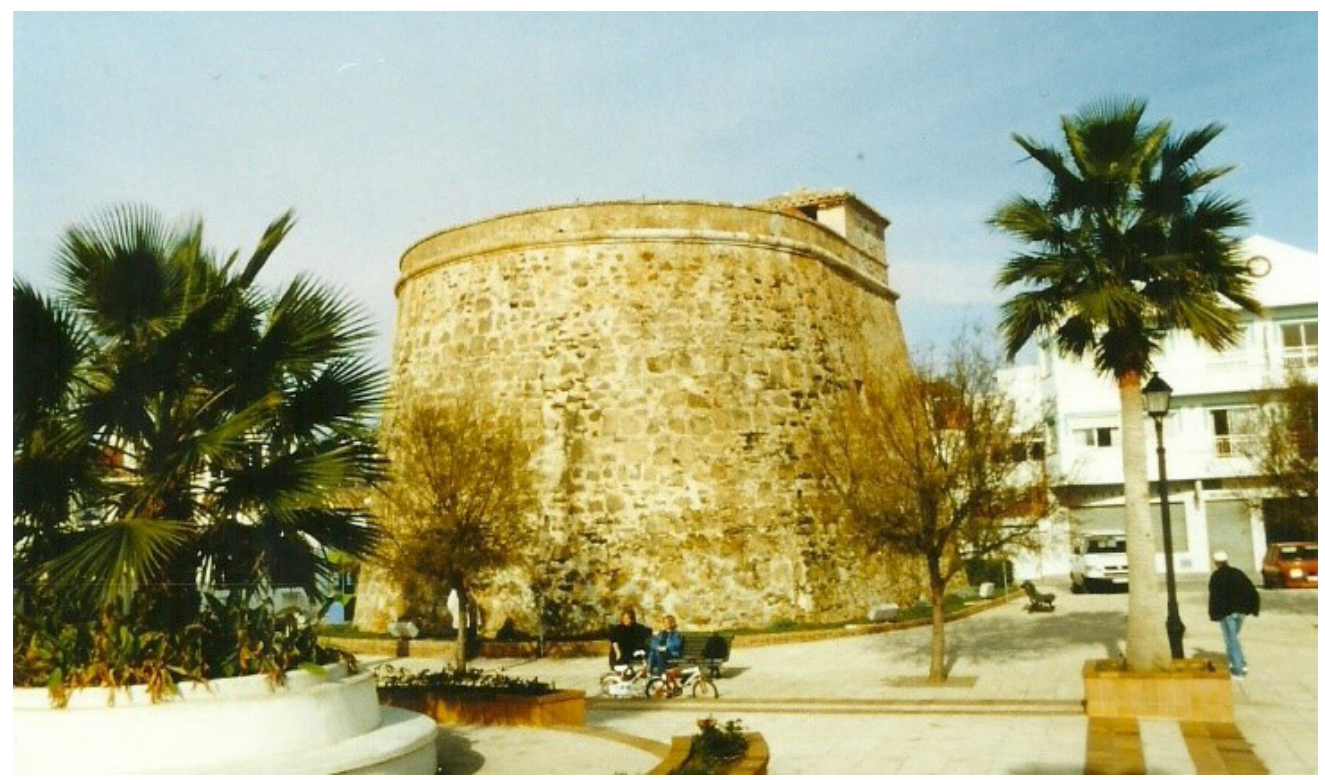

Figura 7. Torre de La Cala (Mijas).

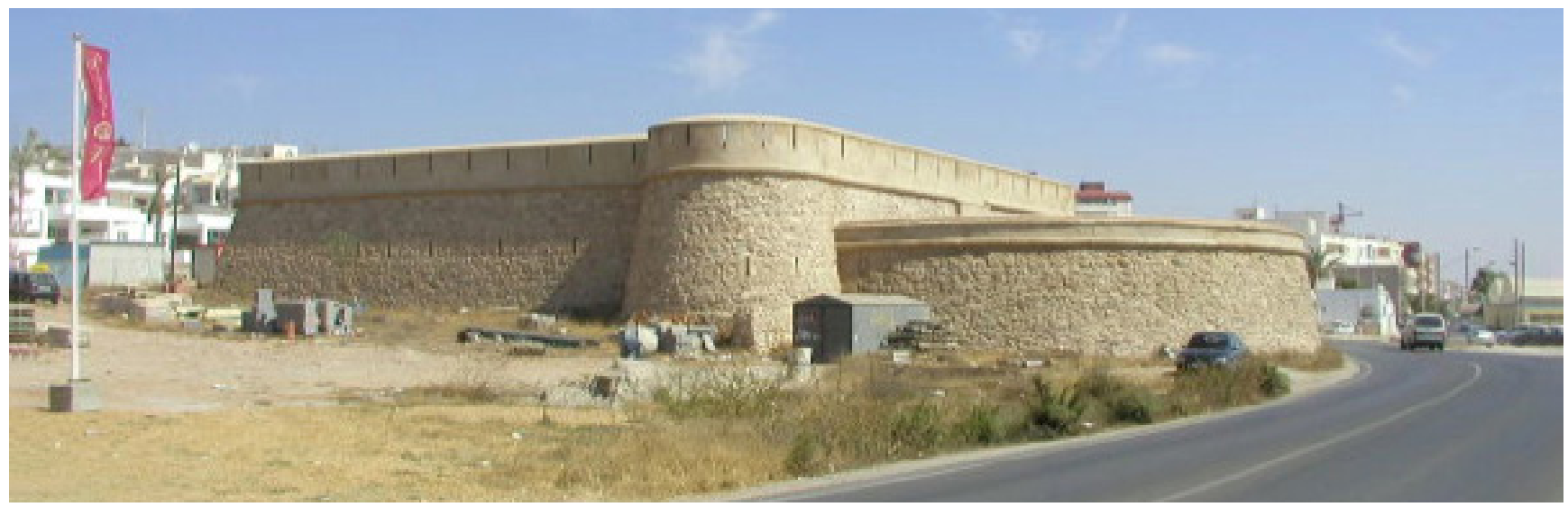

Figura 8. Fuerte-batería de Jesús Nazareno (La Garrucha). 
principal era la defensa contra los ataques ingleses a la costa que se intensificaron desde la toma de Gibraltar en 1704 (Fig. 9). La entrada a la casa fuerte se hace por la cara sur a través de una bella y sólida puerta de entrada en la que aparece en el dintel de piedra el escudo de Carlos III. Dentro y rodeada de un patio se encontraban la zona de acuartelamiento de tropa, las cuadras y pesebres de la caballería, el alojamiento del oficial y sargento, la capilla, cocina, pozo de agua, servicios, almacenes, polvorín, etc. Hace unos años se ha realizado en el fuerte una intervención arquitectónica muy acertada y la casa se ha convertido en museo, sala de exposiciones, de conciertos y eventos culturales, sin afectar para nada a su aspecto externo.

\section{MATERIALES EMPLEADOS EN SU CONSTRUCCIÓN}

Los materiales empleados en la construcción de estas defensas, desde el siglo XV al XVIII son los típicos de la época y del lugar, y es decir: la piedra, generalmente caliza y pizarra, la madera y el ladrillo cocido en horno hormiguero. En las torres cilíndricas, en la de pezuña y en los fuertes la mampostería ordinaria de piedra con ripios era muy empleada en los paramentos vistos, aunque en el macizado interior se empleaban rellenos con grandes piedras y tierra apisonada. Las torres cuadradas se solían construir de aparejo de ladrillo bien cocido predominando los ladrillos santos y recochos. Estos ladrillos se utilizaban también formando verdugadas de dos hiladas para mejorar el asiento de los mampuestos pétreos en las torres de pezuña y fuertes, así como en el perfilado de esquinas o de los espolones en las torres no circulares. En general, en todas las bóvedas de las torres y fuertes construidas con varias roscas superpuestas hemos podido observar la maestría, calidad del ladrillo y el gran cuidado en la ejecución.

\section{CONCLUSIÓN}

El patrimonio que tenemos distribuido a lo largo de unos doscientos kilómetros de costa andaluza formado por torres almenaras, casas fuertes, castillos, etc., tiene una gran importancia histórica y es digno de prestarle la atención y cariño que se merece. Estas torres vigías salvaron la vida de muchos de nuestros antepasados, velaron por la integridad, la libertad y la paz de esta parte de Andalucía y no se merecen el estado de abandono en que se encuentran algunas de ellas, el que sean morada de "ocupas", ni privilegio particular de hacendados.

Somos conscientes de que son muchos los legados culturales e históricos que enriquecen a este trozo de España fruto de las muchas civilizaciones y culturas que se asentaron en él debido a su situación privilegiada en el Mediterráneo. A estos legados hay que sumar la cadena de torres y castillos defensivos de nuestra costa. Es cierto que el mantenimiento, en debidas condiciones, de todo este patrimonio exige un esfuerzo económico, pero también es verdad que mucho de este patrimonio está en un estado casi total de abandono y, muchas veces no por falta de recursos de las Administraciones autónomas o locales, sino por falta de conocimiento y de interés de las mismas y, es que: "más daño que el paso del tiempo lo hace la ignorancia".

Afortunadamente los nativos y los que nos visitan de otros países, las miran con respeto y cariño. Alrededor de muchas de ellas han crecido núcleos de poblacionales importantes: Torremolinos, Torrox, Torre del Mar, etc., o urbanizaciones tan conocidas en la Costa del Sol, como; Torre Muelle, Torre Blanca, Torre Duque, Calahonda, etc. Algunas de estas torres se han restaurado y lucen por la noche, iluminadas por lámparas halógenas de cientos de vatios, como premio al tiempo en que ellas estuvieron iluminando la libertad y seguridad de nuestras costas con sus simples fogatas en sus terrados.

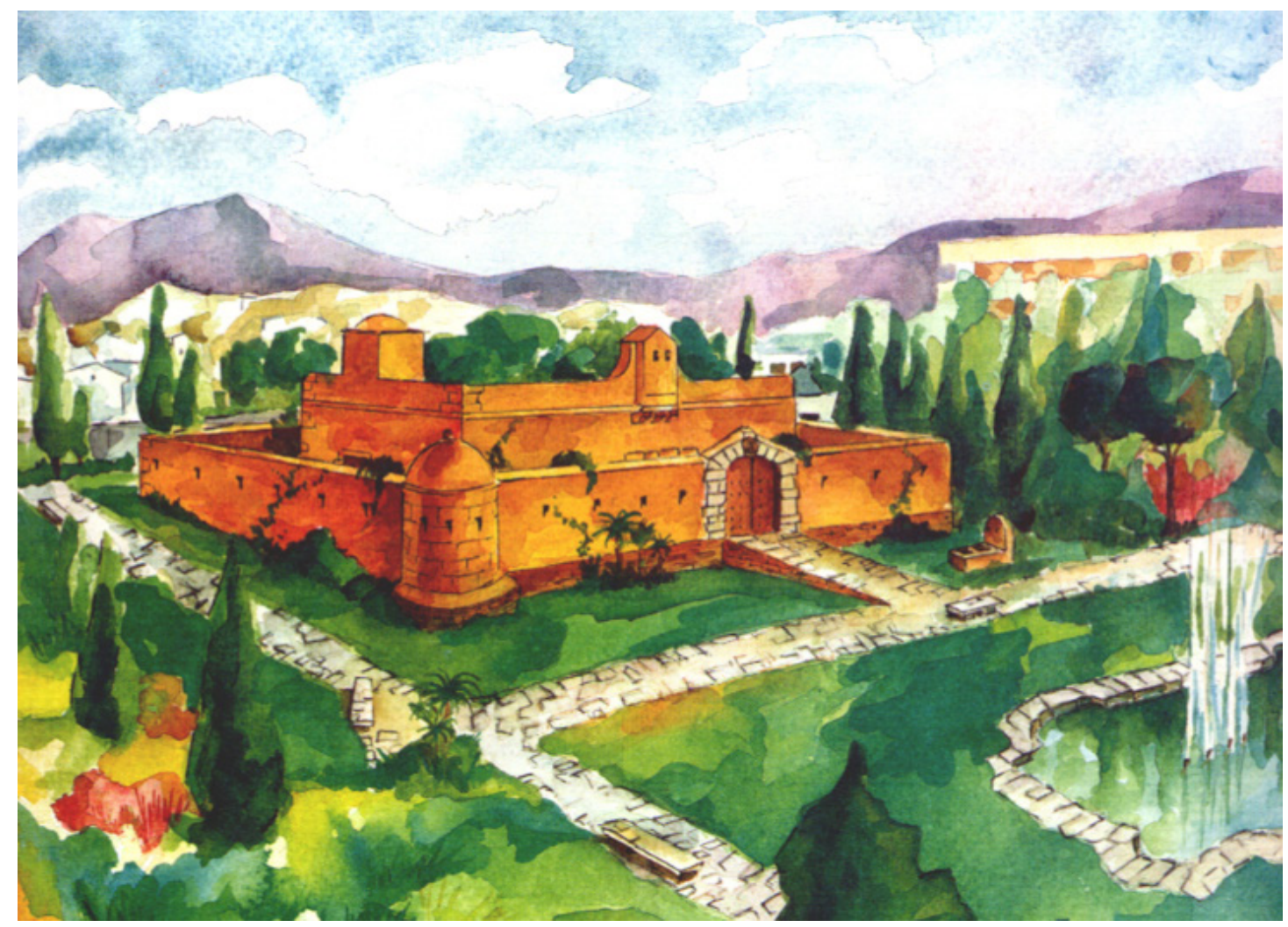

Figura 9. Casa fuerte de Bezmiliana (Rincón de la Victoria). 


\section{BIBLIOGRAFÍA}

(1) Cebrián, J.A. (2009). "La aventura de la Reconquista. La Cruzada del Sur". La Esfera de los libros. Editorial.

(2) Vera Delgado, A. (1986). "La última frontera medieval: La defensa costera en el Obispado de Málaga en tiempo de los Reyes Católicos”. Servicio de Publicaciones de la Excma. Diputación Provincial de Málaga.

(3) Gamir Sandoval, A. (1943). "Organización de la defensa de las costas del reino de Granda desde su reconquista hasta finales del siglo XVI”. Boletín de la Universidad de Granada.

(4) Bejarano Robles, F. (1971). "Documentos históricos de Benalmádena (1501.1512)”. Ayuntamiento de Benalmádena.

(5) Temboury Álvarez, J. (1975). "Torres almenaras (costa occidental)”. Instituto de Cultura. Excma. Diputación Provincial de Málaga. 